\title{
Choice Experiment Method for Sustainable Tourism in Theme Parks
}

\author{
Min-Yen Chang ${ }^{1}$, Yi-Sheng Hsu ${ }^{2}$ and Han-Shen Chen ${ }^{2,3, *(\mathbb{D})}$ \\ 1 Department of Accounting, Jiaxing University, Jiaxing 314001, China; zmy000223@gmail.com \\ 2 Department of Health Diet and Industry Management, Chung Shan Medical University, Taichung City 40201, \\ Taiwan; f8521310@gmail.com \\ 3 Department of Medical Management, Chung Shan Medical University Hospital, Taichung City 40201, Taiwan \\ * Correspondence: allen975@csmu.edu.tw; Tel.: +886-4-2473-0022 (ext. 12225)
}

check for updates

Citation: Chang, M.-Y.; Hsu, Y.-S.; Chen, H.-S. Choice Experiment Method for Sustainable Tourism in Theme Parks. Sustainability 2021, 13, 7146. https://doi.org/10.3390/ su13137146

Academic Editors: Tsung Hung Lee, Fen-Hauh Jan and Pei-Shiang Chang

Received: 1 June 2021

Accepted: 22 June 2021

Published: 25 June 2021

Publisher's Note: MDPI stays neutral with regard to jurisdictional claims in published maps and institutional affiliations.

Copyright: (c) 2021 by the authors. Licensee MDPI, Basel, Switzerland. This article is an open access article distributed under the terms and conditions of the Creative Commons Attribution (CC BY) license (https:// creativecommons.org/licenses/by/ $4.0 /)$.

\begin{abstract}
Previous relevant studies on theme parks lack an exploration of various tourism attributes, e.g., recreational facilities, themes, wait times, fast pass drawings, and pricing, etc., all of which inspired the research motivation of this study. First, the Choice Experiment (CE) method explores tourists' preferences for theme park attributes. Second, the Conditional Logit (CL) and Random Parameter Logit (RPL) models explore the differences in tourists' willingness to pay (WTP) for various attributes from the perspective of their socioeconomic background. We used purposive sampling to survey questionnaire answers face-to-face in Taiwan, and a total of 680 questionnaires were issued, of which, 549 copies are valid, with an effective recovery rate of $80.7 \%$. The research findings suggest the following: (1) The most valued theme park attributes for consumers are the recreational facilities, followed by theme characteristics, and fast pass drawing. (2) Regarding the respondents' WTP for various attributes, they are willing to pay the highest price for thrilling recreational facilities, then for unlimited fast pass services, and cartoon character themes. (3) Respondents believe that if thrilling recreational facilities and fast pass drawing are available at the same time, then the overall effectiveness will be improved. (4) Respondents relatively have no purchase intention for fast pass drawing. It is hoped that the research findings can provide theme park operators reference basis for making plans and decisions.
\end{abstract}

Keywords: theme parks; random utility theory; willingness to pay; tourist preferences; Taiwan

\section{Introduction}

According to World Travel and Tourism Council (WTTC) statistics, in 2019, the tourism industry contributed USD 8.9 trillion to the world economy, accounting for $10.3 \%$ of the global Gross Domestic Product, creating nearly 330 million global job opportunities [1] Therefore, the tourism industry has become one of the important areas that many countries lean on to maintain regional development levels [2,3]. With Taiwan's economic growth and increasing income of its people, there is a growing trend among the Taiwanese citizens to engage in leisure travel, combined with various tourism policies that are actively introduced by the government, for example, Tourism 2020-Development Plan for Sustainable Travel and Tourism Industry in Taiwan, Plan of Action for a Big Tourism Country, and other measures, the number of international tourists visiting Taiwan increased to 11,864,105 in 2019 from 8,016,280 in 2013, for an average annual growth rate of nearly 7\%. Regarding the foreign currency earnings contributed by international tourists, this figure rose to NTD 402.5 billion (USD 14.49 billion) in 2019 from NTD 344.2 billion (USD 12.39 billion) in 2013, with an average annual growth rate of 3.09\% [4]. According to the 2019 Travel and Tourism Competitiveness Report released by the World Economic Forum (WEF) [5], Taiwan's overall "Travel and Tourism Competitiveness Index" (TTCT) ranks twelfth among 140 shortlisted countries, and ranks third among Asian countries, only behind Singapore and Japan. However, the outbreak of COVID-19 in 2020 directly influenced the global 
economy, and WTTC estimated that around the world, there will be 750 million job losses, causing USD 2.1 trillion in economic losses, of which, the tourism industry is the first to suffer. A study by Gabe [6] points out that, with the impact of COVID-19, the number of visitors to theme parks and ticket sales have been slumping; therefore, exploring the issue of sustainable theme park tourism is extremely meaningful.

The sustainable development strategy is a company's timely adaptability when faced with environmental and social issues can also help promote long-term planning and development [7]. Over the past few years, many tourism businesses have been promoting plans for sustainable development of the tourism industry, and have made strategic plans regarding issues in the environment, society, and the economy. The adaptability of the tourism industry is one of the important items of sustainable tourism development, which can help firms adapt to the environment, as well as reducing their losses in the event of disasters [8,9]. Previous studies suggest that the resilience and innovation of tourism companies and organizations can improve their ability in realizing sustainable development, and maintaining competitiveness in the event of disasters $[10,11]$. Therefore, it is necessary for the tourism industry to explore which elements can facilitate the development of sustainable tourism.

In 1955, Walt Disney put his creativity and imagination to work and founded Disneyland in California, after which the development of theme parks began drawing widespread attention. In 1982, after the opening of Epcot Center at Disney World in Florida, the development of theme parks reached a zenith, and the specific concept of theme park was formed. The International Association of Amusement Parks defines a theme park as an area with one or several themes with distinct characteristics, along with recreational facilities, performances, architectural stylings, and food that can be found in this entertainment area. Lukas [12] holds that theme parks not only rely on physical appearance, such as architecture and technology, but are also implemented through environmental and atmospheric design, which enables employees and tourists to role play, leading to a sort of performance enacted between the employees and tourists. Raluca and Gina [13] suggest that theme parks use landscaping, recreational facilities, performances, food \& beverage services, and actors to portray the theme, giving tourists a spatio-temporal experience. As theme parks are becoming more popular, there is the pressure of competition with other amusement parks or the entertainment industry $[14,15]$; therefore, different response strategies are needed to improve competitiveness. As a result, various theme parks have begun using diversification strategies, including using the joint venture with foreign companies or technical cooperation as a selling point, and continuously introducing novel recreational facilities and holding all types of festivals and events to showcase their uniqueness and strengthen their competitive advantage through creative activities and services in efforts to improve tourists' willingness to choose their theme parks [16]. A great number of previous literature explores issues related to theme parks; for example, the customer satisfaction with theme parks [17-20], willingness to revisit the park [17,20], brand loyalty $[19,21]$, service quality [22], and so forth.

A study by Tasci and Milman [23] points out that theme park operators can improve tourists' overall experience value and improve tourist review of the parks by upgrading software and hardware, thereby improving tourists' satisfaction and willingness to revisit $[17,18]$. A study by Milman et al. [19] points out that if tourists feel that the theme park is crowded, then they will have negative affect, thus influencing their degree of satisfaction and loyalty toward the theme park. A study by Fu, et al. [21] points out that the characteristics of theme parks will affect tourists' brand loyalty toward theme parks. A study by Lee et al. [20] points out that developing an effective marketing plan and public promotion will help elevate the overall reputation of theme parks. Pan et al., [24] explore the factors regarding tourists' selection of theme parks, and their findings suggest that tourists value online reviews the most, then the price and type of theme parks. Lari et al. [22] performed research on theme parks in Iran, and their findings show that consumers value service quality the most, with the next being food provisions, and the least being souvenir variety. 
Based on the above literature review, it can be inferred that the recreational facilities, overall atmosphere, specific theme, types of food, and service quality are all important factors determining satisfaction. This study attempts to address a gap in the study, which is whether or not making various product attributes into different combinations can influence the tourism preferences of tourists.

Over the past decades, the Choice Experiment (CE) method has become one of the most common methods to evaluate the consumers' preferences for market and non-market commodities in various fields concerning the applied economics. CE is a type of method of stated preferences (SP) used for economic estimation of commodities and services. In the CE model, commodities and services are described to the consumers by several characteristics and it is assumed that respondents consider all the desired characteristics in estimating and choosing their preferences. In recent years, this method has been widely applied to studies on leisure tourism, for example, hotel selection [25], forest parks [26], national parks [27], international convention tourism [28], air transport services [29], ecotourism [30-32], wetland tourism [33], resorts [34], island tourism [35,36], selection of flight tickets [37], maritime leisure and entertainment [38] and cruise tourism, etc. [39-41].

Song et al. [34] utilizes CE to explore the preference and WTP for casino resorts, and their findings show that consumers have the highest preference for facilities inside the casinos, and they are willing to pay more money to experience quality facilities. Crouch et al. [28] uses CE to explore the international convention tourism, explore tourists' preference for selecting host cities, and their findings show that the most valued attributes by the tourists are the convenience of flight arrival times, risk of the convention being delayed or cancelled, and entry formalities, meanwhile, they emphasize that infrastructure and the convenience of transportation in the cities also influence their competitiveness to host international conventions. Kim and Park [25] use CE to study tourists' hotel selection preference, and their findings show that leisure travelers pay more attention to the overall atmosphere of the hotel, while business travelers pay more attention to the quality and comfort of hotel rooms. Grilli et al. [35] use CE to study the preferences of tourists who visit island states, and their findings show that those tourists who have traveled to island states pay more attention to the environmental protection and environment-related measures of the island, and they are willing to pay extra money if the ecosystem of the island is maintained. Seekamp, et al. [42] use CE to explore tourism in coastal regions, finding that the most valued attribute by tourists is transportation convenience. Randle et al. [43] use CE to examine consumers' preferences in choosing hotels for holidays, and their findings show that the most valued attribute by tourists is price, while the least valued attribute by tourists is availability of parking. Hu and Yang [44] use CE to analyze the consumers' selection of hotels, and find that, when tourists are considering hotel choices, the most valued attribute is the number of reviews and the ratings; while in the booking stage, the most valued attribute is the overall rating. Based on the above literature, it is apparent that previous studies have not used CE to explore different combinations of attributes of theme parks, thereby inspiring the motivation of this study.

Willingness to pay (WTP) for specific product/consumer combinations is important to assist the industry position their products in specific markets. When retailers want to distinguish their products from a cost and price-based commodities type market, they need to know whether consumers will respond accordingly [45]. WTP can be defined as is the maximum price at or below which a consumer will definitely buy one unit of a product. Studies on WTP either relate to consumers' response to perceived quality attributes or their actual response after experiencing intrinsic quality attributes of the product. A study by Chiambaretto [46] uses the conjoint analysis to explore WTP for in-flight services, and their findings show that leisure travelers are willing to pay an additional amount of EUR 26.6 to purchase flights with relatively more variety of food, while the in-flight Wi-Fi has negative significance, indicating that leisure travelers pay less attention to this attribute. A study by Kang and Nicholls [47] found that $44.3 \%$ of the consumers are willing to pay an additional amount of USD100 to choose eco-friendly hotels, while only $17 \%$ of the consumers are not 
willing to pay an extra amount for hotels with green facilities, indicating that consumers generally attach great importance to environmental issues. Rodella et al. [48] studied the coastal region tourism and beach maintenance costs in Italy, and their findings show that consumers are willing to pay about EUR 15 per person per year to protect the beaches and maintain their appearance. Iranah et al. [49] explore tourists' WTP for forest protection in small and medium-sized islands, and their findings show that international tourists are willing to pay an extra amount of USD 7.73 and domestic tourists are willing to pay an extra amount of USD 3.74 for protecting the biodiversity of forests. Platania and Rizzo [50] explore the WTP of tourists visiting the national parks reserve regions, and their findings show that $89 \%$ of the tourists are willing to pay an extra amount of EUR 5 per ticket to protect the environment and biodiversity of the national parks. The above shows that WTP is often used to explore the value of various attributes, therefore, this study will utilize WTP to examine the tourists' WTP and preference for various product attributes.

Based on the above, since Taiwan's theme parks receive nearly 11 million visitors per year and is one of the main players of the travel, tourism and service industry in Taiwan, this study will conduct research on five attributes of theme parks, namely, recreational facilities, theme characteristics, fastpass drawing, wait times, and prices. It will develop the model of influencing factors and WTP of theme parks, and explore the relationship between tourists' preference for attributes of theme parks and their WTP through empirical analysis. The research findings can provide a reference for businesses to carry out strategic planning, as well as evaluation and analysis for future planning and improvement of theme parks.

There are four sections in the rest of this article. The method and econometric models applied in the article are described in the Section 2. The results are reported and explored in the Section 3. Conclusions and some implications of the study are presented in the Section 4.

\section{Materials and Methods}

\subsection{Combination Schemes of Product Attributes and Levels of Theme Parks}

This study explores the product attributes of theme parks, namely, recreational facilities, theme characteristics, fastpass drawing, wait times, and prices, and proposes the level of various product attributes according to the current status and characteristics of theme parks in Taiwan, as shown in Table 1.

In order to make it easier for respondents to fill out the questionnaire, this study adopts the orthogonal design method (using the Orthogonal Experimental Design of SPSS) to select $216(3 \times 4 \times 2 \times 3 \times 3)$ combinations, and then removes redundant schemes, generating seven schemes and one current status scheme. One choice set will be generated by combining the current status with two schemes randomly (as shown in Figure 1), so each questionnaire has three choice sets, and after completing the matching, there will be seven versions of questionnaires. 
Table 1. Product Attributes and Levels of Theme Parks.

\begin{tabular}{|c|c|c|}
\hline Attributes & Description of Attributes & Levels \\
\hline Recreation facilities & $\begin{array}{l}\text { According to the current status of Taiwan's } \\
\text { theme parks, this study classifies recreational } \\
\text { facilities as entertaining and exciting. The } \\
\text { entertainment facilities are usually relaxing } \\
\text { and soothing, such as, the merry-go-round } \\
\text { and big wheel; thrill rides are those with a } \\
\text { fast-paced and stimulating experience, such } \\
\text { as, roller coasters and hot wheel. }\end{array}$ & $\begin{array}{l}\text { (1) } 50 \% \text { entertainment facilities and } 50 \% \text { thrill } \\
\text { rides } \\
\text { (2) } 70 \% \text { entertainment facilities and } 30 \% \text { thrill } \\
\text { rides } \\
\text { (3) } 30 \% \text { entertainment facilities and } 70 \% \text { thrill } \\
\text { rides }\end{array}$ \\
\hline Theme characteristics & $\begin{array}{l}\text { Currently, the theme of Taiwan's theme parks } \\
\text { are mostly about rides and games, which are } \\
\text { used in their operating activities. }\end{array}$ & $\begin{array}{l}\text { (1) Rides and games; } \\
\text { (2) Cartoon characters; } \\
\text { (3) Culture \& history; } \\
\text { (4) Movie-themed tourism }\end{array}$ \\
\hline
\end{tabular}

The fastpass drawing activity was created by Disney, which allows tourists to go to specific attraction during a specific time to participate in a lucky drawing where they Fastpass lucky drawing can win an fastpass. There is a chance of winning the fastpass of that attraction. This activity aims to reduce wait times for popular facilities by distributing tourists to wait for different facilities.

(1) No lucky drawing mechanism (maintain the current status)

(2) Lucky drawing mechanism in place

Currently, in Taiwan's theme parks, the average wait times for one attraction is about 15-20 min, which may vary due to peak or off-peak hours, and peak or off season. Based on the number of facilities that one tourist Wait times purchases, the fastpass services can be used to get clearance. On average, one can save 20 min for one attraction, and if using the fastpass for six recreational facilities, about 2 $\mathrm{h}$ of wait times can be saved. However, none of Taiwan's theme parks provide this service.

(1) No fastpass services

(2) fastpass services for two facilities

(3) Unlimited fastpass services

This study refers to the ticket price of four major theme parks in Taiwan (the baseline ticket price is NTD 750 (USD 27)) to design the research, takes into account the level of wait times, and sets the price difference at NTD 150 (USD 5.4). Combinations of different attributes will be priced accordingly.

(1) NTD 750 (USD 27);

(2) NTD 900 (USD 32.4);

(3) NTD 1050 (USD 37.8)

Note 1: NTD, new Taiwan dollar (1 NTD = 0.036 USD).

The formal questionnaire mainly surveys tourists between the ages of 15-30 who have visited theme parks. The questionnaire design of this study comprises two parts and is presented in Appendix A. The first part is CE choice sets which combine various product attributes into different schemes, so that respondents can choose the scheme according to their preference; the second part investigates the socioeconomic background information of respondents, including gender, age, profession, and average monthly income. The following explains the implications of various product attributes: 


\begin{tabular}{|c|c|c|c|}
\hline & Current Status & Schedule A & Schedule B \\
\hline \multicolumn{4}{|l|}{$\begin{array}{l}\text { Recreation } \\
\text { facilities }\end{array}$} \\
\hline & $\begin{array}{cc}\text { thrilling } & \text { entertaining } \\
\mathbf{5 0} \% & \mathbf{5 0} \%\end{array}$ & $\begin{array}{c}\text { thrilling } \\
\mathbf{3 0 \%}\end{array}$ & $\begin{array}{c}\text { entertaining } \\
50 \%\end{array}$ \\
\hline $\begin{array}{c}\text { Theme } \\
\text { characteristics }\end{array}$ & Rides and Games & Rides and Games & Culture \& History \\
\hline $\begin{array}{c}\text { Fastpass Lucky } \\
\text { Drawing }\end{array}$ & $\begin{array}{l}\text { No lucky drawing } \\
\text { mechanism (maintain the } \\
\text { current status) }\end{array}$ & Lucky Drawing Mechanism & Lucky Drawing Mechanism \\
\hline Wait Times & No Fastpass Services & $\begin{array}{c}\text { Fastpass Services for Two } \\
\text { Facilities }\end{array}$ & Unlimited Fastpass Services \\
\hline Price & NTD $\$ 750(\mathrm{USD} \$ 27)$ & NTD\$ 1050(USD $\$ 37.8)$ & NTD\$ 900(USD\$32.4) \\
\hline $\begin{array}{l}\text { Check Your } \\
\text { Selection }\end{array}$ & $\square$ & $\square$ & $\square$ \\
\hline
\end{tabular}

Note 1 : NTD, new Taiwan dollar (1 NTD = 0.036 USD).

Figure 1. Example Questionnaire Choice Set.

\subsubsection{Recreational Facilities}

Commodities provided by theme parks are a joyful and relaxing experience, and the need for play appeals to tourists who want sensory stimulation and feelings of satisfaction. all of this attracts visitors to the recreational facilities and go to theme parks [51]. When a theme park adds a new recreational attraction, it will not only boost the number of visitors, but also extend the stay time of tourists and thus increase the amount of consumption in the park [52]. Tourists go to amusement parks and ride the recreational facilities for mental relaxation and sensory stimulation [53]. The above research illustrates that the recreational attraction is one of the important factors for tourists when considering whether or not they want to visit; therefore, this study uses recreational facilities as one of the attributes for exploration.

\subsubsection{Theme Characteristics}

A theme park is an artificial, surreal environment that is created purposefully. It is a recreational venue with a special atmosphere, which could be a theme of a specific history or special landscape, or a myth or legend, or a combination of the two themes or various themes, for example, the Disneyland Main Street Electrical Parade, which can further enhance the theme and improve the park's appeal [18,21]. A good theme will 
endow product characteristics and seize the corresponding market; therefore, the selection and utilization of theme is of great importance, and thus this study explores this aspect.

\subsubsection{Fastpass Drawing}

In a theme park, it is very common for people to wait to enjoy the recreational facilities, such as rides and games. If the wait times get too long, tourists' perception of the crowding of park's rides and attractions will be significantly increased [54]. In order to reduce the time of waiting in line during the peak hours, increase the overall efficiency of the theme park, and reduce time cost for tourists, the fastpass drawing can help cut wait times, and improve tourist satisfaction [55]. Therefore, this study refers to the "fastpass drawing" of Disneyland and incorporates this attribute.

\subsubsection{Wait Times}

The study by Chuo and Heywood [54] shows that waiting for too long in a theme park cause negative emotions in tourists, thereby influencing their review of the theme park, it is for this reason that companies must adopt strategies to reduce the negative impacts on consumers due to wait times [56-58].

This study conducts pretest survey on tourists' average wait times for one attraction and degree of importance attached to fastpass, and the findings show that on average tourists wait for $15 \mathrm{~min}$ for one attraction, and the time may vary between peak and offpeak hours or peak and off season. Secondly, tourists generally believe that it is important to set up fastpass mechanism. Due to the fact that the fastpass service is not well established in Taiwan, this study refers to the "fastpass service" of the Universal Studios and adds this attribute.

\subsubsection{Pricing}

A study by Varki and Colgate [59] emphasizes that ticket price will impact the rate of tourist revisits to various theme parks. Studies point out that price perception has direct and significant impacts on willingness to repurchase and revisit $[59,60]$. Therefore, this study explores the price attribute.

\subsection{Model Selection and Analysis}

First, this study uses CE to develop the utility model for theme park attributes. Then, it applies the CL and RPL models to estimate the theme park utility function, and explores the differences in WTP for various attributes from the perspective of socioeconomic backgrounds of respondents. The specifics are reported in the following:

\subsubsection{RPL}

Hypothetically, in $t$ number of scenarios, individuals $(n=1, \ldots, N)$ have $j$ number of alternative schemes. Choice $t$, supposes the individual $n$ considers the alternative schemes provided by all information, and selects the alternative scheme $j$ which has the highest utility, as shown in Formula (1):

$$
U_{j t n}=\sum_{k=1}^{k} \beta_{n k} X_{j n k}+\varepsilon_{j t n}=\beta^{\prime}{ }_{n} X_{j t n}+\varepsilon_{j t n}
$$

In this formula, the observable variable related to the scheme and characteristics of decision maker;

$\beta_{n}$ : random variable;

$\varepsilon_{j t n}$ : unobservable error term of the decision maker.

In order to allow the error terms of different alternative schemes to have correlation, the additional random element $\beta_{n}$ is added to bring heteroskedasticity and correlation between alternative schemes, as shown in (2):

$$
\beta_{n}=b_{n}+\Delta Z_{n}+\Gamma v_{n}=b_{n}+\Delta z_{n}+\eta_{n}
$$


In this formula, $Z_{n}$ : observable data of decision maker $n$;

$\eta_{n}$ : random terms that are distributed according to potential parameters.

For the decision maker $n$, the probability of choosing path $i$ in the alternative paths set $P_{i n}$ is as shown in Formula (3):

$$
\begin{gathered}
P_{\text {in }}=\int L_{\text {in }}(\beta) f(\beta) d \beta=\int L_{\text {in }}(\beta) f(\beta \mid \theta) \beta d \beta \\
L_{\text {in }}(\beta)=\frac{e^{V_{j n}(\beta)}}{\sum_{j=1}^{J} e^{V_{j n}(\beta)}}=\frac{e^{\beta x_{i n}}}{\sum_{j=1}^{J} e^{\beta x_{j n}}}
\end{gathered}
$$

In this formula,

$P_{i n}$ : the probability for the decision maker $n$ to choose scheme $i$;

$L_{\text {in }}(\beta)$ : choice probability of RPL; $\theta$ : mean, standard deviation, and co-variance, etc. of the density of the probability function;

$f$ : mixture distribution.

\subsubsection{CL}

The CL model mainly assumes that respondents have the same preference, and since all respondents have the same preference for certain attributes, each attribute can be used for parameter estimation. To extract more information and understand the heteroskedasticity of various preferences, socioeconomic backgrounds can be used as alternative-specific constants (ASC) or the interactive effects between attributes, and then they can be incorporated into the utility function [61], as shown in Formula (4):

$$
V_{i j}=A S C_{j}+\sum_{k} \beta_{k} X_{i j k}+\sum_{m} \theta_{j m} A S C_{j} * S_{m i}+\sum_{k} \delta_{k n} X_{i j k} * S_{n i}
$$

where, $\theta_{j m}$ is the coefficient vector of the interactive effect between ASC and socioeconomic background feature $m$ of individual $i ; \delta_{\mathrm{kn}}$ is the coefficient vector of the interactive effect between attribute $k$ and socioeconomic background feature $n$ of individual $i\left(\mathrm{~S}_{n i}\right)$.

\subsubsection{WTP for Attributes}

The above model can calculate the WTP for attributes at different levels, and the estimation method is as follows: divide the marginal utility of attributes by the marginal utility of price, then obtain the negative value, i.e., marginal rate of substitution $[62,63]$. The calculation for WTP is as shown in Formula (5):

$$
W T P=-\frac{\frac{\partial V}{\partial X_{k}}}{\frac{\partial V}{\partial p}}=-\frac{\beta_{k}}{\beta_{p}}
$$

where, $V$ is the measurable utility, $k$ is the estimated coefficients of non-price attributes, and $p$ is the estimated coefficients of price attribute.

\section{Results}

\subsection{Sample Size and Composition}

This study adopts the purposive sampling method and interviews people between the ages of 15-30 who have visited theme parks. This study uses a face-to-face questionnaire to survey tourists who have visited theme parks in Taiwan, and the investigation period is from January 2021 to March 2021. A total of 680 questionnaires were issued, 549 valid questionnaires remain after removing invalid ones, making the effective recovery rate reach $80.7 \%$. With regards to respondents' gender, females are the majority $(52.7 \%)$, and males take up less percentage (47.3\%). Age-wise, most of the respondents are between the ages of $15-18$, totaling 226 people ( $41.2 \%)$, followed by 183 people between the ages of $19-23$ $(33.3 \%)$, and then 140 people between the ages of 24-30 (25.5\%). In terms of the profession, students have the highest proportion, totaling 330 individuals $(60.1 \%)$, followed by the service industry, 92 people (16.8\%), and then self-employed, for a total of 55 individuals 
$(10 \%)$. Regarding personal average income per month, the majority is at the level of NTD 20,000 (USD 720) and below, totaling 329 individuals (59.9\%), followed by the level of NTD 20,000-40,000 (USD 720-1440), 162 individuals (29.4\%), and then the level of NTD 40,000-60,000 (USD 1440.3-2160) (8.2\%).

\subsection{Choice Sets of Theme Parks}

The analysis results show that the most preferred scheme by tourists is the current scheme, with a product combination featuring " $50 \%$ thrilling facilitiesrides and $50 \%$ entertainment facilities, the theme of rides and games, no fastpass drawing, no fastpass services, and ticket price of NTD 750 (USD 27)" (accounting for 37.46\%), followed by the combination featuring " $50 \%$ thrill rides and $50 \%$ entertainment facilities, the theme of movie tourism, fastpass drawing available, no fastpass services, and ticket price of NTD 750 (USD 27)" (accounting for 17.18\%). The least preferred scheme by tourists is the combination featuring " $50 \%$ thrill rides and $50 \%$ entertainment facilities, the theme of culture and history, fastpass drawing available, unlimited fastpass services, and ticket price of NTD 900 (USD 32.4)." This study deduces that possibly due to the fact that consumers between the ages of 15-30 are relatively disinterested in the theme of culture and history, and pay less attention to fastpass services, while caring most about the price. This result is in line with the finding by Ryan, Shih, and Huan, who suggest that the ticket price is the factor influencing the satisfaction of theme park visitors [64].

\subsection{Analysis Results of CL and RPL}

Based on the Random Utility Function (1), this study constructs the utility model for attributes of theme parks, for the purpose of understanding tourists' consumption preference for theme parks, it further modifies the Random Utility Theory model to develop Formula (6):

$$
U_{i j}=\alpha_{1} F A C_{i j}+\alpha_{2} T H E_{i j}+\alpha_{3} R E W_{i j}+\alpha_{4} R E W_{i j}+\beta M O N E Y_{i j}+\varepsilon_{i j}
$$

where, $i=1,2,3 \ldots, 549$, the sample size is 549 .

We use the CL and RPL models via NLOGIT4.0 to process Formula (6), and estimate the value of coefficients of various attributes of theme parks, and the empirical analysis results are collated in Table 2. Among them, the CL model assesses respondents' average preference for theme park attributes, and the RPL model assesses respondents' heterogeneous preferences for theme park attributes. The research results show that both the results of CL and RPL models suggest that respondents prefer to change the current situation; the CL model indicates that respondents only prefer thrill rides, while the RPL model suggests that respondents prefer thrill rides as well as fastpass drawing. Moreover, both the results of CL and RPL show that respondents do not prefer entertainment facilities, the themes of cartoon characters, culture and history, as well as wait times. Furthermore, the RPL also shows the heteroskedasticity distribution of respondents' preferences for various attribute parameters. Based on Table 2, it can be seen that, at the significance level of $1 \%$, when maintaining the current status, recreational facilities $\left(F A C_{1}\right)$ and wait times $\left(\mathrm{WAT}_{2}\right)$ both indicate significance, meaning that heterogeneity exists in tourists preferences for the two attributes, recreational facilities and wait times. 
Table 2. Empirical Estimations of CL and RPL Models.

\begin{tabular}{|c|c|c|c|c|c|c|c|c|}
\hline \multirow{2}{*}{$\begin{array}{l}\text { Attribute and Level } \\
\text { Attribute Variables }\end{array}$} & \multicolumn{2}{|c|}{ CL } & \multirow[b]{2}{*}{ WTP } & \multirow[b]{2}{*}{ Coefficient } & \multirow[b]{2}{*}{$t$ Value } & RPL & \multirow[b]{2}{*}{$t$ Value } & \multirow[b]{2}{*}{ WTP } \\
\hline & Coefficient & $t$ Value & & & & Standard Deviation Coefficient & & \\
\hline Maintain current status (ASC) & -2.536 & $-2.923 * *$ & & -3.436 & $-4.531^{* * *}$ & 1.046 & 3.21 & \\
\hline Recreational Facilities (FAC1) & -0.992 & $-4.892 * * *$ & 99.2 & -1.292 & $-6.621 * * *$ & 0.222 & 1.67 & 53.8 \\
\hline Recreational Facilities (FAC2) & 0.526 & $2.407^{* *}$ & 52.6 & 1.419 & $3.264^{* * *}$ & 0.385 & $2.52^{* * *}$ & 59.1 \\
\hline Theme characteristics (THE1) & -0.491 & $-2.019 *$ & 49.1 & -0.631 & $-1.642 *$ & 1.218 & 1.48 & 26.3 \\
\hline Theme characteristics (THE2) & 0.698 & $-2.870 * *$ & 69.8 & 0.426 & $-3.405^{*}$ & 0.520 & 0.64 & 17.8 \\
\hline Theme characteristics (THE3) & -0.244 & -0.108 & 24.4 & -0.498 & -0.243 & 1.234 & 0.97 & 20.8 \\
\hline Fastpass Drawing (REW) & -0.352 & $-2.925^{* *}$ & 35.2 & -0.434 & $5.375^{*}$ & 0.679 & 1.34 & 18.1 \\
\hline Wait Times (WAT1) & -0.369 & -1.322 & 36.9 & -0.684 & $-2.987^{*}$ & 0.164 & $0.52 * *$ & 28.5 \\
\hline Wait Times (WAT2) & -0.211 & -1.348 & 21.1 & -0.795 & $-6.248^{* * *}$ & 0.943 & 1.64 & 33.1 \\
\hline Price (MONEY) & -0.01 & -0.356 & & -0.024 & $-0.234^{* *}$ & & & \\
\hline Number of Choice Sets & \multicolumn{2}{|c|}{1647} & & & \multicolumn{4}{|c|}{1647} \\
\hline Log-likelihood Ratio & \multicolumn{2}{|c|}{-1677.102} & & & \multicolumn{2}{|r|}{-1067.346} & & \\
\hline
\end{tabular}

Note $1:{ }^{* * *},{ }^{* *}$, and ${ }^{*}$ are significant at $1 \%, 5 \%$, and $10 \%$, respectively. Note $2: \mathrm{FAC}_{1}: 70 \%$ entertainment facilities and $30 \%$ thrill rides; FAC 2 : $30 \%$ entertainment facilities and $70 \%$ thrill rides; $\mathrm{THE}_{1}$ : the theme of cartoon characters; $\mathrm{THE}_{2}$ : the theme of culture and history; $\mathrm{THE}_{3}$ : the theme of movie tourism; REW: lucky drawing available; $\mathrm{WAT}_{1}$ : fastpass services for two facilities; $\mathrm{WAT}_{2}$ : unlimited fastpass services; MONEY: ticket price.

Then, we use the value of coefficients estimated by Random Utility Function (1) in the theoretical Model (5), and obtain the respondents WTP for attribute $X_{j k}$ of product $j$. According to the CL model, the WTP for various attributes are: NTD 99.2 (USD 3.57) for recreational facilities $\left(\mathrm{FAC}_{1}\right)$, NTD 52.6 (USD 1.89) for recreational facilities $\left(\mathrm{FAC}_{2}\right)$, NTD 49.1 (USD 1.77) for theme characteristics $\left(\mathrm{THE}_{1}\right)$, NTD 69.8 (USD 2.51) for theme characteristics $\left(\mathrm{THE}_{2}\right), \mathrm{NTD} 24.4$ (USD 0.88) for theme characteristics $\left(\mathrm{THE}_{3}\right), \mathrm{NTD} 35.2$ (USD 1.27) for fastpass drawing (REW), NTD 26.9 (USD 0.97) for wait times $\left(\mathrm{WAT}_{1}\right.$ ), and NTD 21.1 (USD 0.76) for wait times $\left(\mathrm{WAT}_{2}\right)$. According to the RPL model, the WTP for various attributes are: NTD 59.1 (USD 2.13) for recreational facilities $\left(\mathrm{FAC}_{2}\right)$, NTD 53.8 (USD 1.94) for recreational facilities $\left(\mathrm{FAC}_{1}\right)$, NTD 26.3 (USD 0.95) for theme characteristics (THE 1 ), NTD 17.8 (USD 0.64) for theme characteristics (THE 2 ), NTD 20.8 (USD 0.75) for theme characteristics $\left(\mathrm{THE}_{3}\right.$ ), NTD 18.1 (USD 0.65) for fastpass drawing (REW), NTD 28.5 (USD 1.03) for wait times ( $\left(\mathrm{WAT}_{1}\right)$, and NTD 33.1 (USD 1.19) for wait times $\left(\mathrm{WAT}_{2}\right)$.

\subsection{Explorations of Socioeconomic Backgrounds of Respondents on the Heterogeneity of WTP for Theme Parks}

According to the analysis results of the RPL model, "recreational facilities $\left(\mathrm{FAC}_{2}\right)$ " and "wait times $\left(\mathrm{WAT}_{1}\right)$ " have random parameters; therefore, this study compares the WTP related to the two attributes and the socioeconomic backgrounds of the respondents. The results are listed in Table 3, and the WTP for recreational facilities $\left(\mathrm{FAC}_{2}\right)$ showcases significant differences in terms of profession and personal average income per month, among which, the respondents who are students and earn NTD 20,000 (USD 720) or less per month have a relatively higher level of WTP, indicating that students are more willing to pay for theme parks with more thrill rides. The WTP for wait times $\left(\mathrm{WAT}_{1}\right)$ showcases significant differences in age and personal average income per month, among which, respondents between the ages of 24-30 earn NTD 20,001-40,000 (USD 720-1440) per month and have a relatively higher level of WTP. From the results, it can be seen that the younger people and those who earn NTD 20,001-40,000 (USD 720-1440) per month pay more attention to fastpass drawing, and hope to reduce wait times through this activity; therefore, they are willing to pay relatively more for theme parks that offer fastpass drawing. 
Table 3. Explorations of Socioeconomic Backgrounds of Respondents on the Heterogeneity of WTP for Theme Parks.

\begin{tabular}{|c|c|c|c|c|c|c|c|c|}
\hline & \multirow{2}{*}{ Socioeconomic Background } & \multirow{2}{*}{ Sample Size } & \multicolumn{2}{|c|}{ ASC } & \multicolumn{2}{|c|}{$\mathrm{FAC}_{2}$} & \multicolumn{2}{|c|}{ REW } \\
\hline & & & Mean & $t$ Value & Mean & $t$ Value & Mean & $t$ Value \\
\hline \multirow{2}{*}{ Gender } & Male & 260 & -6672.27 & \multirow{2}{*}{2.14} & 1056.64 & \multirow{2}{*}{2.69} & 1024.98 & \multirow{2}{*}{-3.193} \\
\hline & Female & 289 & -7793.23 & & 1057.53 & & 1059.87 & \\
\hline \multirow{3}{*}{ Age } & $15-18$ years old & 226 & -4632.13 & \multirow{3}{*}{$-2.98 * *$} & 1098.21 & \multirow{3}{*}{1.79} & 1034.31 & \multirow{3}{*}{$2.14 * * *$} \\
\hline & 19-23 years old & 183 & -3249.24 & & 1038.42 & & 1048.35 & \\
\hline & $24-30$ years old & 140 & -7643.15 & & 1069.24 & & 962.54 & \\
\hline \multirow{6}{*}{ Profession } & Students & 330 & -4321.89 & \multirow{6}{*}{1.19} & 964.25 & \multirow{6}{*}{$2.43^{* * *}$} & 989.78 & \multirow{6}{*}{1.54} \\
\hline & Military, Public Servants \& Teachers & 46 & -6498.17 & & 1034.79 & & 1046.52 & \\
\hline & Service Industry & 92 & -6952.94 & & 1054.28 & & 1078.98 & \\
\hline & Self-employed & 55 & -5972.15 & & 1035.17 & & 1034.56 & \\
\hline & Engineers & 15 & -4698.27 & & 1043.27 & & 1088.55 & \\
\hline & Others & 11 & -6531.46 & & 1004.93 & & 1010.14 & \\
\hline \multirow{6}{*}{$\begin{array}{l}\text { Average } \\
\text { personal wage } \\
\text { per month }\end{array}$} & NTD\$20,000 (USD\$720)and below & 329 & -8.597 .22 & \multirow{6}{*}{$1.73^{*}$} & 1047.46 & \multirow{6}{*}{$2.11^{* *}$} & 1201.46 & \multirow{6}{*}{$2.153 * *$} \\
\hline & $\begin{array}{l}\text { NTD } \$ 20,001-40,000 \\
\text { (USD } \$ 720-1440)\end{array}$ & 162 & -7342.6 & & 1039.57 & & 984.56 & \\
\hline & $\begin{array}{l}\text { NTD\$40,001-60,000 } \\
\text { (USD } \$ 1440-2160)\end{array}$ & 46 & -6678.15 & & 1026.34 & & 1079.65 & \\
\hline & $\begin{array}{l}\text { NTD\$ 60,001-80,000 } \\
\text { (USD \$2160-2880) }\end{array}$ & 9 & -7067.38 & & 998.14 & & 978.98 & \\
\hline & $\begin{array}{l}\text { NTD } \$ 80,001-100,000 \\
\text { (USD\$2880-3600) }\end{array}$ & 3 & -7498.19 & & 1058.33 & & 1034.21 & \\
\hline & $\begin{array}{l}\text { NTD\$100,000 } \\
\text { (USD\$3600) and above }\end{array}$ & 2 & -6438.25 & & 1079.44 & & 1077.88 & \\
\hline
\end{tabular}

Note $1:{ }^{* *},{ }^{* *}$, and $*$ are significant at $1 \%, 5 \%$, and $10 \%$, respectively. Note 2 : NTD, new Taiwan dollar $(1 \mathrm{NTD}=0.036$ USD).

\section{Discussion}

According to the analysis results of the CL model, it is found that the recreational facilities $\left(F A C_{1}\right)$ have the highest figure at a negative significance level, indicating that the theme parks need to discount the price by NTD 99.2 (USD 3.57) so that respondents will be willing to visit theme parks with $70 \%$ of entertainment facilities and $30 \%$ of thrill rides. The second highest figure is related to theme characteristics $\left(\mathrm{THE}_{2}\right)$, meaning that the respondents are only willing to visit theme parks with the cultural and historical theme if the price is discounted by NTD 69.8 (USD 2.51). By contrast, the recreational facilities $\left(\mathrm{FAC}_{2}\right)$ display a positive significance level, with a WTP of NTD 52.6 (USD 1.89), indicating that respondents are willing to pay an additional amount of NTD 52.6 (USD 1.89) to visit the theme parks with more thrill rides, and this finding is in line with that of Milman [65], who proposes that theme parks will pay more attention to the design of thrill rides in order to attract tourists. According to the research findings by Fu et al. [66], the most valued factor of theme parks by tourists is safe facilities, followed by thrill rides. The research shows that recreational facilities exert huge impacts on tourists' choice of theme parks.

Based on the RPL analysis results, the WTP for recreational facilities $\left(F_{A} C_{2}\right)$ is the highest, showing that respondents are willing to pay an extra amount of NTD 59.1 (USD 2.13) to visit theme parks with more thrill rides, and this finding is in line with that of Milman [50], who points out that recreational facilities are tools for creating joyful experiences, and tourists will visit theme parks for more thrill rides. In terms of fastpass drawing (REW), it is revealed that respondents are willing to pay an extra amount of NTD 18.1 (USD 0.65) to visit theme parks with such an attribute, and this finding is in line with the study by Chuo and Heywood [54], who point out that when tourists wait for too long in line, their perception of the crowding will be enhanced, suggesting the importance of fastpass drawing. Wu et al. [17] believe that wait times is an important factor influencing tourists' intention to revisit. The studies by Baker [67], Disney World [68], and Milman [69] all point out that theme parks with relatively a large number of visitors can provide fastpass tickets, paid fastpass drawing coupons, or more interactive activities for people waiting in 
line, so as to ameliorate consumers' negative emotions caused by waiting in line, as well as improve operational efficiency at peak hours.

The above analysis shows that tourists have great differences in their preferences for product attributes and levels of theme parks. This finding is in line with Heo and Lee [70], who suggest that tourists who care more about wait times are willing to pay relatively more to purchase fastpass services. The study by Ryan et al. [64] suggests that the factors influencing tourist satisfaction about theme parks include the atmosphere of theme parks, thrill rides, whether or not it is crowded, and ticket price. Moreover, the study by Hernandez-Maskivker et al. [71] points out that tourists with relatively high income are willing to purchase fastpass services in order to save time.This finding is also in line with the aforementioned studies.

\section{Conclusions}

\subsection{Findings}

This study presented some viewpoints: (1) The most valued theme park attributes for tourists are the thrilling recreational facilities, followed by theme characteristics, and fast pass drawing. (2) Regarding the respondents' WTP for various attributes, they are willing to pay the highest price for thrilling recreational facilities, then for unlimited fast pass services, and cartoon character themes. (3) According to the models, student groups prefer thrilling recreational facilities over entertaining. (4) Regarding the explorations of socioeconomic backgrounds of respondents, young people with income are willing to purchase fastpass services to reduce waiting times.

\subsection{Managerial Implications}

According to the research findings, tourists prefer thrill rides more than entertainment facilities, and if a theme park has fastpass drawing activities, then it can further attract tourists to spend money, and the tourists are willing to pay an additional amount. Therefore, it is recommended that theme park businesses refer to the findings of this research, and prioritize the design of thrill rides when adding new recreational facilities, as well as adjusting ticket pricing; with regards to the fastpass drawing. Since Taiwan's theme parks only use online APP for ticket booking currently, it is suggested that theme park businesses refer to the practices of foreign theme parks (e.g., Disneyland), and add this product attribute in efforts to reduce wait times for tourists and improve competitiveness of sustainable tourism.

Moreover, results of fastpass services and theme characteristics all indicate negative significance levels, suggesting that fastpass services will result in tourists' negative feelings, or if using one particular theme as the characteristic may reduce consumption intention of tourists. Therefore, when it comes to the provision of fastpass services, it is recommended that the parks take into account the number of visitors during peak and off-peak seasons, working days, and holidays, so as to decide whether to provide this kind of services; moreover, the services can be targeted at a specific group of visitors, so that resource input can be allocated to attributes that are preferred by the tourists. However, tourists do not pay attention to various theme characteristics, and therefore it can be reasoned that they pay more attention to the type of recreational facilities, price, and other attributes. Thus, it is recommended that theme park businesses further explore recreational facilities and pricing, and give tourists more options.

Based on the results of empirical analysis, the respondents who are students and earn NTD 20,000 (USD 720) or less per month have a relatively higher level of WTP for the combination featuring " $30 \%$ entertainment facilities and $70 \%$ thrill rides," so theme parks businesses should further study the thrill rides that are favored by tourists, and design more ways of playing. respondents between the ages of 24-30 and earn NTD 20,001-40,000 (USD 720-1440) per month have a significant preference for "fastpass services for two facilities," indicating that younger people who are on a payroll will purchase fastpass services due to the length of wait times. Given that no theme park in Taiwan has provided 
fastpass services so far, it is recommended that relevant businesses sell this kind of service to certain groups, so as to improve the operational efficiency and increase operating income.

\subsection{Research Limitations and Directions for Future Studies}

This study had some limitations in the research process. In the future, the research framework will be more comprehensive if the scope of research is expanded. This study proposes the following suggestions regarding the research conclusions:

First, this study only configures five attributes (recreational facilities, theme characteristics, fastpass drawing, wait times, and price), and for the purpose of further understanding tourists' preferences and WTP for theme parks of different kinds and with different attributes, more attributes (such as the following: online reviews, stay time, etc.) can be added into future studies.

Second, the survey respondents of this study are mainly the younger generation between the ages of 15-30; however, theme parks have shown diversification in their development over the recent years (for example, adding outlets and hotels), and they also attract tourists of different age groups. Therefore, it is recommended that future studies can carry out explorations based on different age groups and formulate relevant marketing strategies to attract different customer groups to visit and spend money at the theme park.

Author Contributions: Three co-authors had together contributed to the completion of this article. Formal analysis; investigation; data curation and writing-original draft preparation, M.Y.C.; investigation, data curation, review and editing, Y.-S.H.; writing-original draft preparation, writing-review and editing, H.-S.C. All authors have read and agreed to the published version of the manuscript.

Funding: This research received no external funding.

Institutional Review Board Statement: Not applicable.

Informed Consent Statement: Not applicable.

Data Availability Statement: The data presented in this study are available on request from the corresponding author. The data are not publicly available due to the privacy and ethical.

Acknowledgments: I would like to express my sincere appreciation to all the experts who have taken the time to review this article and provide lots of valuable comments.

Conflicts of Interest: The author declares no conflict of interest. 


\section{Appendix A. Questionnaire}

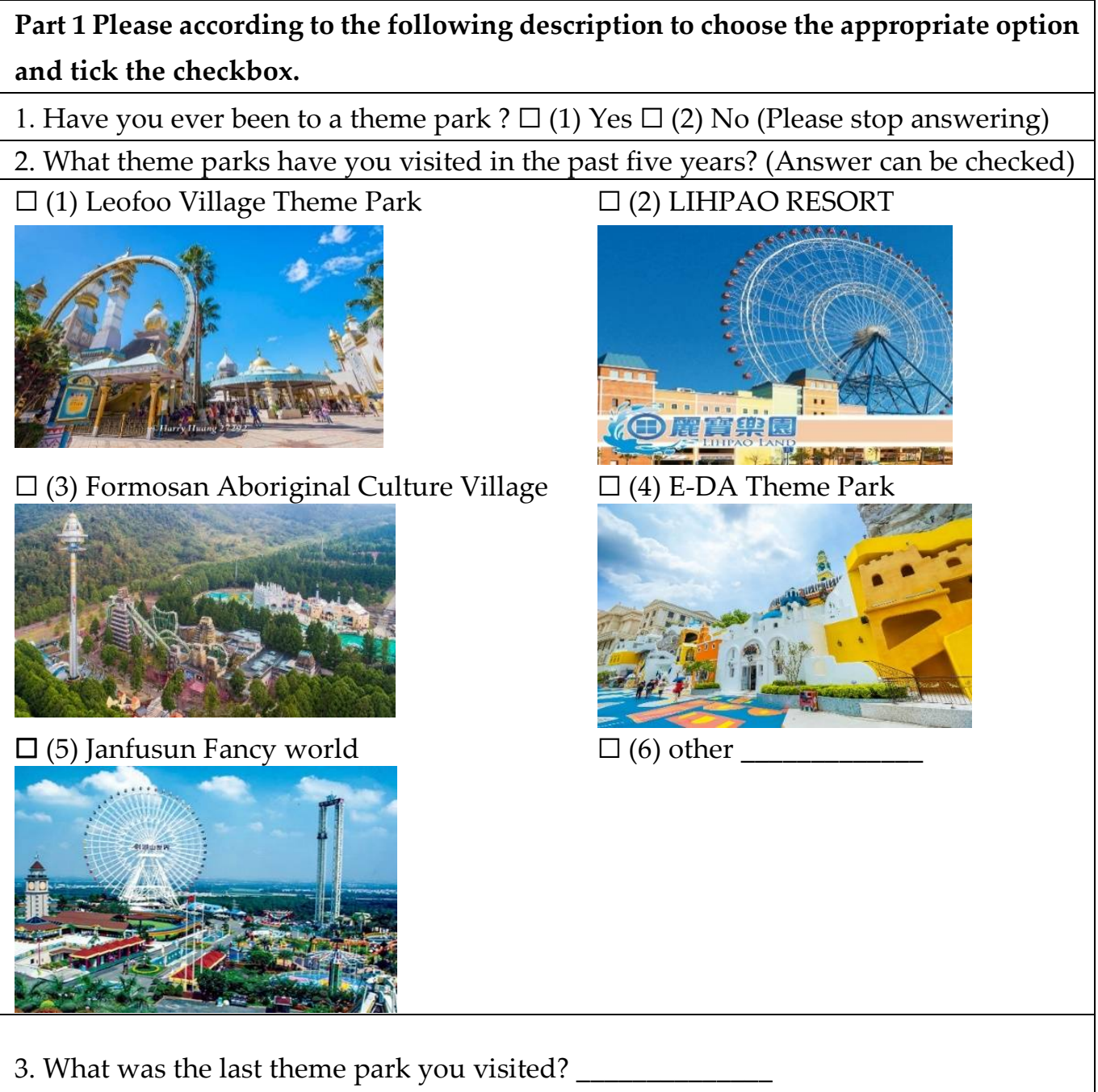

\section{References}

1. World Travel and Tourism Council (WTTC). Economic Impact Reports. 2020. Available online: https://wttc.org/Research/ Economic-Impact (accessed on 12 March 2021).

2. Dodds, R.; Butler, R. The phenomena of overtourism: A review. Int. J. Tour. Cities 2019, 5, 519-528. [CrossRef]

3. Brida, J.G.; Risso, W.A. Hierarchical structure of the German stock market. Expert Syst. Appl. 2010, 37, 3846-3852. [CrossRef]

4. The Tourism Bureau of the Ministry of Transportation and Communications of Taiwan. 2019. Available online: https://eng. taiwan.net.tw/ (accessed on 22 June 2020).

5. World Economic Forum (WEF). Travel and Tourism Competitiveness Index (TTCT). Available online: http:/ / www3.weforum org/docs/WEF_TTCR_2019.pdf (accessed on 18 July 2020).

6. Gabe, T.; Florida, R. Impacts of Jobs Requiring Close Physical Proximity and High Interaction with the Public on US Industry Employment Change During the Early Stages of the COVID-19 Pandemic. BE J. Econ. Anal. Policy 2021. [CrossRef]

7. Kasemsap, K. Environmental management and waste management: Principles and applications. In Ethics and Sustainability in Global Supply Chain Management; IGI Global: Hershey, PA, USA, 2017; pp. 26-49.

8. Lew, A.A. Scale, change and resilience in community tourism planning. Tour. Geogr. 2014, 16, 14-22. [CrossRef]

9. Faber, M.H.; Miraglia, S.; Qin, J.; Stewart, M.G. Bridging resilience and sustainability-decision analysis for design and management of infrastructure systems. Sustain. Resilient Infrastruct. 2020, 5, 102-124. [CrossRef]

10. De Carvalho, A.O.; Ribeiro, I.; Cirani, C.B.S.; Cintra, R.F. Organizational resilience: A comparative study between innovative and non-innovative companies based on the financial performance analysis. Int. J. Innov. 2016, 4, 58-69. [CrossRef]

11. Akgün, A.E.; Keskin, H. Organisational resilience capacity and firm product innovativeness and performance. Int. J. Prod. Res. 2014, 52, 6918-6937. [CrossRef]

12. Lukas, S.A. How the theme park gets its power: Lived theming, social control, and the themed worker self. In The Themed Space: Locating Culture, Nation, and Self; Lanham: Lexington, MD, USA, 2007; pp. 1-22. 
13. Raluca, D.C.; Gina, S. Theme park-The main concept of tourism industry development. Ann. Univ. Oradea Econ. Sci. Ser. 2008, 17, 641-646.

14. Clavé, S.A. The Global Theme Park Industry; CABI: London, UK, 2007.

15. Milman, A.; Li, X.; Wang, Y.; Yu, Q. Examining the guest experience in themed amusement parks: Preliminary evidence from China. J. Vacat. Mark. 2012, 18, 313-325. [CrossRef]

16. McClung, G.W. Theme park selection: Factors influencing attendance. Tour. Manag. 2012, 18, $233-245$.

17. Wu, H.C.; Li, M.Y.; Li, T. A study of experiential quality, experiential value, experiential satisfaction, theme park image, and revisit intention. J. Hosp. Tour. Res. 2018, 42, 26-73. [CrossRef]

18. Milman, A.; Tasci, A.D. Exploring the experiential and sociodemographic drivers of satisfaction and loyalty in the theme park context. J. Destin. Mark. Manag. 2018, 8, 385-395. [CrossRef]

19. Milman, A.; Tasci, A.D.; Wei, W. Crowded and popular: The two sides of the coin affecting theme-park experience, satisfaction, and loyalty. J. Destin. Mark. Manag. 2020, 18, 100468. [CrossRef]

20. Lee, S.; Jeong, E.; Qu, K. Exploring theme park visitors' experience on satisfaction and revisit intention: A utilization of experience economy model. J. Qual. Assur. Hosp. Tour. 2020, 21, 474-497. [CrossRef]

21. Fu, X.; Kang, J.; Tasci, A. Self-congruity and flow as antecedents of attitude and loyalty towards a theme park brand. J. Travel Tour. Mark. 2017, 34, 1261-1273. [CrossRef]

22. Lari, L.; Jabeen, F.; Iyanna, S. Prioritising theme park service quality in Islamic contexts: An analytic hierarchy process approach. Int. J. Cult. Tour. Hosp. Res. 2020, 14, 225-237. [CrossRef]

23. Tasci, A.D.; Milman, A. Exploring experiential consumption dimensions in the theme park context. Curr. Issues Tour. 2019, 22, 853-876. [CrossRef]

24. Pan, H.; Bahja, F.; Cobanoglu, C. Analysis of US theme park selection and international implications. J. Transnatl. Manag. 2018, 23, 22-38. [CrossRef]

25. Kim, D.; Park, B.J.R. The moderating role of context in the effects of choice attributes on hotel choice: A discrete choice experiment. Tour. Manag. 2017, 63, 439-451. [CrossRef]

26. Zong, C.; Cheng, K.; Lee, C.H.; Hsu, N.L. Capturing tourists' preferences for the management of community-based ecotourism in a forest park. Sustainability 2017, 9, 1673. [CrossRef]

27. Juutinen, A.; Mitani, Y.; Mäntymaa, E.; Shoji, Y.; Siikamäki, P.; Svento, R. Combining ecological and recreational aspects in national park management: A choice experiment application. Ecol. Econ. 2011, 70, 1231-1239. [CrossRef]

28. Crouch, G.I.; Del Chiappa, G.; Perdue, R.R. International convention tourism: A choice modelling experiment of host city competition. Tour. Manag. 2019, 71, 530-542. [CrossRef]

29. Balcombe, K.; Fraser, I.; Harris, L. Consumer willingness to pay for in-flight service and comfort levels: A choice experiment. J. Air Transp. Manag. 2009, 15, 221-226. [CrossRef]

30. Chaminuka, P.; Groeneveld, R.A.; Selomane, A.O.; Van Ierland, E.C. Tourist preferences for ecotourism in rural communities adjacent to Kruger National Park: A choice experiment approach. Tour. Manag. 2012, 33, 168-176. [CrossRef]

31. Hearne, R.R.; Salinas, Z.M. The use of choice experiments in the analysis of tourist preferences for ecotourism development in Costa Rica. J. Environ. Manag. 2002, 65, 153-163. [CrossRef] [PubMed]

32. Duijndam, S.; Beukering, P.; Fralikhina, H.; Molenaar, A.; Koetse, M. Valuing a Caribbean coastal lagoon using the choice experiment method: The case of the Simpson Bay Lagoon, Saint Martin. J. Nat. Conserv. 2020, 56, 125845. [CrossRef]

33. Carlsson, F.; Frykblom, P.; Liljenstolpe, C. Valuing wetland attributes: An application of choice experiments. Ecol. Econ. 2003, 47, 95-103. [CrossRef]

34. Song, H.; Wang, J.; Lyu, S.O. Willingness to pay for casino-based integrated resorts: A choice experiment. J. Destin. Mark. Manag. 2021, 19, 100555.

35. Grilli, G.; Tyllianakis, E.; Luisetti, T.; Ferrini, S.; Turner, R.K. Prospective tourist preferences for sustainable tourism development in Small Island Developing States. Tour. Manag. 2021, 82, 104178. [CrossRef]

36. Mejía, C.V.; Brandt, S. Managing tourism in the Galapagos Islands through price incentives: A choice experiment approach. Ecol. Econ. 2015, 117, 1-11. [CrossRef]

37. Hossain, I.; Saqib, N.U.; Haq, M.M. Scale heterogeneity in discrete choice experiment: An application of generalized mixed logit model in air travel choice. Econ. Lett. 2018, 172, 85-88. [CrossRef]

38. Wielgus, J.; Gerber, L.R.; Sala, E.; Bennett, J. Including risk in stated-preference economic valuations: Experiments on choices for marine recreation. J. Environ. Manag. 2009, 90, 3401-3409. [CrossRef]

39. Mahadevan, R.; Chang, S. Valuing shipscape influence to maximise cruise experience using a choice experiment. Int. J. Hosp. Manag. 2017, 67, 53-61. [CrossRef]

40. Vogel, M.; Papathanassis, A.; Wolber, B. The Business and Management of Ocean Cruises; CABI: London, UK, 2012.

41. Kwortnik, R.J. Shipscape influence on the leisure cruise experience. Int. J. Cult. Tour. Hosp. Res. 2008, 2, 289-311. [CrossRef]

42. Seekamp, E.; Jurjonas, M.; Bitsura-Meszaros, K. Influences on coastal tourism demand and substitution behaviors from climate change impacts and hazard recovery responses. J. Sustain. Tour. 2019, 27, 629-648. [CrossRef]

43. Randle, M.; Kemperman, A.; Dolnicar, S. Making cause-related corporate social responsibility (CSR) count in holiday accommodation choice. Tour. Manag. 2019, 75, 66-77. [CrossRef] 
44. Hu, X.S.; Yang, Y. Determinants of consumers' choices in hotel online searches: A comparison of consideration and booking stages. Int. J. Hosp. Manag. 2020, 86, 102370. [CrossRef]

45. Grunert, K.G.; Bredahl, L.; Brunsø, K. Consumer perception of meat quality and implications for product development in the meat sector-A review. Meat Sci. 2004, 66, 259-272. [CrossRef]

46. Chiambaretto, P. Air passengers' willingness to pay for ancillary services on long-haul flights. Transp. Res. Part E Logist. Transp. Rev. 2021, 147, 102234. [CrossRef]

47. Kang, S.; Nicholls, S. Determinants of willingness to pay to stay at a green lodging attraction. Int. J. Hosp. Manag. 2021, 94, 102834. [CrossRef]

48. Rodella, I.; Madau, F.; Mazzanti, M.; Corbau, C.; Carboni, D.; Utizi, K.; Simeoni, U. Willingness to pay for management and preservation of natural, semi-urban and urban beaches in Italy. Ocean Coast. Manag. 2019, 172, 93-104. [CrossRef]

49. Iranah, P.; Lal, P.; Wolde, B.T.; Burli, P. Valuing visitor access to forested areas and exploring willingness to pay for forest conservation and restoration finance: The case of small island developing state of Mauritius. J. Environ. Manag. 2018, 223, 868-877. [CrossRef]

50. Platania, M.; Rizzo, M. Willingness to pay for protected areas: A case of Etna Park. Ecol. Indic. 2018, 93, 201-206. [CrossRef]

51. Milman, A. The future of the theme park and attraction industry: A management perspective. J. Travel Res. 2001, 40-42, 139-147. [CrossRef]

52. Cornelis, P.C. Effects of co-branding in the theme park industry: A preliminary study. Int. J. Contemp. Hosp. Manag. 2010, 22, 775-796. [CrossRef]

53. Kao, Y.F.; Huang, L.S.; Wu, C.H. Effects of theatrical elements on experiential quality and loyalty intentions for theme parks. Asia Pac. J. Tour. Res. 2008, 13, 163-174. [CrossRef]

54. Chuo, H.Y.; Heywood, J.L. An Optimal Queuing Wait for Visitors' Most Favorite Ride at Theme Parks. In Advances in Hospitality and Leisure; Emerald: Bingley, UK, 2014; pp. 57-73.

55. Gill, S. An analysis of Disney Theme Parks' relational approaches to developing consumer engagement and advocacy. J. Promot. Commun. 2018, 6, 236-248.

56. Mishalani, R.G.; McCord, M.M.; Wirtz, J. Passenger wait time perceptions at bus stops: Empirical results and impact on evaluating real-time bus arrival information. J. Public Transp. 2006, 9, 5. [CrossRef]

57. Allen, J.; Muñoz, J.C.; de Dios Ortúzar, J. Modelling service-specific and global transit satisfaction under travel and user heterogeneity. Transp. Res. Part A Policy Pract. 2018, 113, 509-528. [CrossRef]

58. Lekhawichit, N.; Chavaha, C.; Chienwattanasook, K.; Jermsittiparsert, K. The impact of service quality on the customer satisfaction: Mediating role of wait times. Psychol. Educ. J. 2021, 58, 3113-3125.

59. Varki, S.; Colgate, M. The role of price perceptions in an integrated model of behavioral intentions. J. Serv. Res. 2001, 3, 232-240. [CrossRef]

60. Cakici, A.C.; Akgunduz, Y.; Yildirim, O. The impact of perceived price justice and satisfaction on loyalty: The mediating effect of revisit intention. Tour. Rev. 2019, 74, 443-462. [CrossRef]

61. Baskaran, R.; Cullen, R.; Colombo, S. Estimating values of environmental impacts of dairy farming in New Zealand. N. Z. J. Agric. Res. 2009, 52, 377-389. [CrossRef]

62. Hensher, D.A.; Rose, J.; Greene, W.H. The implications on willingness to pay of respondents ignoring specific attributes. Transportation 2005, 32, 203-222. [CrossRef]

63. Bechtold, K.B.; Abdulai, A. Combining attitudinal statements with choice experiments to analyze preference heterogeneity for functional dairy products. Food Policy 2014, 47, 97-106. [CrossRef]

64. Ryan, C.; Shih Shuo, Y.; Huan, T.C. Theme parks and a structural equation model of determinants of visitor satisfaction-Janfusan Fancyworld, Taiwan. J. Vacat. Mark. 2010, 16, 185-199. [CrossRef]

65. Milman, A.; Okumus, F.; Dickson, D. The global theme park industry. Worldw. Hosp. Tour. Themes 2010, 2, 220-237. [CrossRef]

66. Fu, X.; Kang, J.; Hahm, J.J.; Wiitala, J. Investigating the consequences of theme park experience through the lenses of self-congruity and flow. Int. J. Contemp. Hosp. Manag. 2020, 32, 1181-1199. [CrossRef]

67. Baker, C.A. Creative choices and fan practices in the transformation of theme park space. Transform. Work. Cult. 2016, 22. [CrossRef]

68. Disney World. Extra Magic Hours. 2020. Available online: https://disneyworld.disney.go.com/guest-services/extra-magichours / (accessed on 21 December 2020).

69. Milman, A. Visitor management in highly-visited attractions: Lessons that practitioners can learn from the US theme park industry and the national parks. In Overtourism: Tourism Management and Solutions; Routledge: New York, NY, USA, 2019; pp. 104-124.

70. Heo, C.Y.; Lee, S. Application of revenue management practices to the theme park industry. Int. J. Hosp. Manag. 2009, $28,446-453$. [CrossRef]

71. Hernandez-Maskivker, G.M.; Nicolau, J.L.; Ryan, G.; Valverde, M. A reference-dependent approach to WTP for priority. Tour. Manag. 2019, 71, 165-172. [CrossRef] 